\section{Commentary: Intraoperative graft patency assessment: Just do it!}

\author{
Derrick Y. Tam, MD, PhD, and \\ Stephen E. Fremes, MD, MSc, FRCSC
}

Drs Akhrass and Bakaeen ${ }^{1}$ provided an informative summary and expert surgeon's overview of the benefits and potential risks of intraoperative graft assessment for coronary bypass graft surgery. The early and late outcomes of coronary bypass surgery are contingent on the reproducible construction of fully patent anastomoses with quality conduits to important coronary targets. The authors have reviewed the key tools used to assess graft patency intraoperatively. We agree with the authors that transit time flowmetry (TTFM), particularly when combined with epicardial ultrasound (ECUS), provides the surgeon with reassurance of graft functionality. TTFM is a Class IIa recommendation in the 2018 European Revascularization Guidelines. ${ }^{2}$ The use of flowmetry is not a substitute for comprehensive clinical assessment and technical precision but is meant to supplement clinical assessment and uncompromising execution. However, a common observation is that intraoperative graft failure, while infrequent, may be unheralded and without other clinical cues.

Given the controversy surrounding the EXCEL trial, the prognostic importance of perioperative myocardial infarction has been questioned. ${ }^{3}$ Yet, it is well accepted that clinically defined perioperative myocardial infarction is not a benign event and is commonly associated with graft occlusion. Biancari and colleagues, ${ }^{4}$ in a meta-analysis of 9 studies of 1104 patients with perioperative myocardial infarction, reported early mortality was $12.6 \%$. Graft failure was present in $62 \%$ of patients taken to the catheterization laboratory and in $79.8 \%$ of patients taken directly back to the operating room without angiography.

From the Division of Cardiac Surgery, Schulich Heart Centre, Department of Surgery, Sunnybrook Health Sciences Centre, University of Toronto, Toronto, Ontario, Canada.

Disclosures: The authors reported no conflicts of interest.

The Journal policy requires editors and reviewers to disclose conflicts of interest and to decline handling or reviewing manuscripts for which they may have a conflict of interest. The editors and reviewers of this article have no conflicts of interest.

Received for publication Feb 10, 2021; revisions received Feb 10, 2021; accepted for publication Feb 22, 2021; available ahead of print Feb 27, 2021.

Address for reprints: Stephen E. Fremes, MD, MSc, FRCSC, Sunnybrook Health Sciences Centre, 2075 Bayview Ave, Room H4 05, Toronto, Ontario, M4N 3M5 Canada (E-mail: stephen.fremes@sunnybrook.ca).

JTCVS Techniques 2021;7:138-9

2666-2507

Copyright (c) 2021 The Authors. Published by Elsevier Inc. on behalf of The American Association for Thoracic Surgery. This is an open access article under the CC BY-NCND license (http://creativecommons.org/licenses/by-nc-nd/4.0/).

https://doi.org/10.1016/j.xjtc.2021.02.038

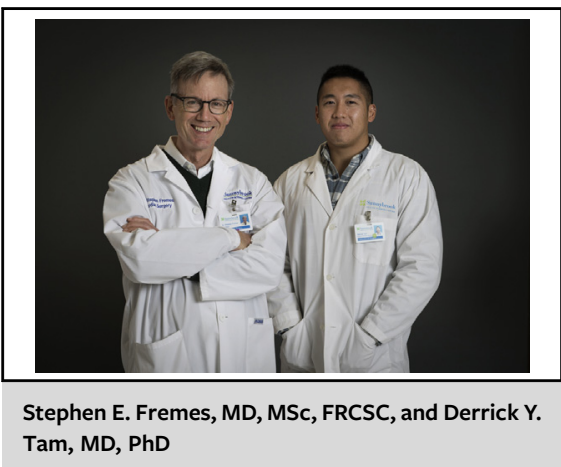

CENTRAL MESSAGE

Systematic transit time flowme-

try of grafts is recommended to complement thorough clinical evaluation, although surgical judgment is essential before graft revision, as false positives can

occur.

The evidence supporting the practice is largely observational. In the only randomized trial comparing TTFM with indocyanine green fluorescent angiography (ICG), the sensitivity to detect $50 \%$ graft stenosis or occlusion was far greater with ICG ( $83 \%$ vs $25 \%$ ) according to early postoperative angiography-as nonocclusive stenoses may not result in flow disturbances. ${ }^{5}$ Also, when ICG and TTFM were compared with usual care in a later randomized controlled trial that was likely underpowered, intraoperative graft assessment was not associated with improved graft patency at 1 year; however, graft stenosis alone was numerically lower $(3 / 160,5.5 \%$ vs $8 / 152,15.4 \%$, $P=.09$ ). ${ }^{6}$ In a meta-analysis of 35 TTFM studies (almost entirely observational) including 8943 patients and 15,673 grafts, graft revision on a per-patient basis was $4.3 \%$ and $2.0 \%$ on a per-graft basis. ${ }^{7}$ However, graft revision was performed in only $25.1 \%$ of abnormal grafts, indicating the importance of combining TTFM with clinical judgment. Abnormal TTFM results were associated with graft occlusion and worse short-term clinical outcomes. ${ }^{7}$

The authors caution that falsely positive findings can be seen in certain patient scenarios leading to unnecessary graft revision, which, in turn, may then lead to patient harm. We concur with the authors that ECUS is complementary to TTFM, mainly in the identification of TTFM false positives. Di Giammarco and associates ${ }^{8}$ reported in a consecutive patient series including 717 grafts analyzed with both TTFM and ECUS that ECUS identified only 3 
of $678(0.4 \%)$ TTFM false negatives but determined that 35 of 39 TTFM positive grafts were false positives. Durable graft patency is necessary for favorable long-term outcomes following coronary surgery. There is considerable evidence that conduit is the key driver. ${ }^{9-11}$ That said, quality assurance is imperative. One of the potential limitations of the methodology is the number of false positives from TTFM alone. It is essential that TTFM findings are not used in isolation but are combined with careful clinical assessment. However, poor decision-making may result from a lack of familiarity with the technology and the reporting. That speaks to the importance to routinely check graft patency intraoperatively, ie, just do it!

\section{References}

1. Akhrass R, Bakaeen FG. Intraoperative graft patency validation: friend or foe? J Thorac Cardiovasc Surg Tech. 2021;7:131-7.

2. Neumann FJ, Sousa-Uva M, Ahlsson A, Alfonso F, Banning AP, Benedetto U, et al; ESC Scientific Document Group. 2018 ESC/EACTS guidelines on myocardial revascularization. Eur Heart J. 2019;4:87-165.

3. Stone GW, Kappetein AP, Sabik JF, Pocock SJ, Morice MC, Puskas J, et al; EXCEL Trial Investigators. Five-year outcomes after PCI or CABG for left main coronary disease. $N$ Engl J Med. 2019;381:1820-30.
4. Biancari F, Anttila V, Dell'Aquila AM, Airaksinen JKE, Brascia D. Control angiography for perioperative myocardial Ischemia after coronary surgery: metaanalysis. J Cardiothorac Surg. 2018;13:24.

5. Desai ND, Miwa S, Kodama D, Koyama T, Cohen G, Pelletier MP, et al. A randomized comparison of intraoperative indocyanine green angiography and transit-time flow measurement to detect technical errors in coronary bypass grafts. J Thorac Cardiovasc Surg. 2006;132:585-94.

6. Singh SK, Desai ND, Chikazawa G, Tsuneyoshi H, Vincent J, Zagorski BM, et al. The Graft Imaging to Improve Patency (GRIIP) clinical trial results. J Thorac Cardiovasc Surg. 2010;139:294-301.e1.

7. Thuijs DJFM, Bekker MWA, Taggart DP, Kappetein AP, Kieser TM, Wendt D, et al. Improving coronary artery bypass grafting: a systematic review and meta-analysis on the impact of adopting transit-time flow measurement. Eur J Cardiothorac Surg. 2019;56:654-63.

8. Di Giammarco G, Canosa C, Foschi M, Rabozzi R, Marinelli D, Masuyama S, et al. Intraoperative graft verification in coronary surgery: increased diagnostic accuracy adding high-resolution epicardial ultrasonography to transit-time flow measurement. Eur J Cardiothorac Surg. 2014;45:e41-5.

9. Gaudino M, Benedetto U, Fremes S, Biondi-Zoccai G, Sedrakyan A, Puskas JD, et al; RADIAL Investigators. Radial-artery or saphenous-vein grafts in coronaryartery bypass surgery. $N$ Engl J Med. 2018;378:2069-77.

10. Lamy A, Eikelboom J, Sheth T, Connolly S, Bosch J, Fox KAA, et al. Rivaroxaban, aspirin, or both to prevent early coronary bypass graft occlusion: the COMPASS-CABG study. J Am Coll Cardiol. 2019;73:121-30.

11. Gaudino M, Hameed I, Robinson NB, Ruan Y, Rahouma M, Naik A, et al. Angiographic patency of coronary artery bypass conduits: a network meta-analysis of randomized trials. J Am Heart Assoc. 2021;10:e019206. 